\title{
O teletrabalho nos tempos da velocidade e da aceleração
}

\author{
Nilton Rodrigues da Paixão Júnior ${ }^{1}$
}

\section{Resumo}

O teletrabalho se revelou como nova forma de prestação de serviço fora do clássico ambiente de trabalho. A tecnologia da informação permite essa nova forma de trabalho. O modelo antigo de prestação de serviço num local determinado, normalmente dentro do espaço empresarial, se tornou flexível. A tecnologia da informação torna o mundo cada vez menor e os espaços de trabalho cada vez mais diversos.

Palavras-chaves: trabalho remoto; teletrabalho; home office; direito à desconexão; sociedade do cansaço.

\section{Teleworking in times of speed and acceleration}

\begin{abstract}
Teleworking has been shown itself as a new way of providing services outside the classic working environment. Information technology allows this new way of working. The old model of providing services in a specific place, usually within the business space, has become flexible. Information technology makes the world smaller and smaller and workspaces increasingly diverse.
\end{abstract}

Keywords: remote work; teleworking; home office; right to disconnect; burn out society.

\section{INTRODUÇÃO}

Falar em teletrabalho pressupõe dizer sobre o trabalho, uma categoria analítica de suma importância. Analisar o trabalho exige ter em mente a noção de não trabalho. Como a vida não se limita ao trabalho, ou pelo menos deveria ser assim, é imperioso não afastar do debate a complexidade que é o viver, a existência humana.

Os tempos são de velocidade e de aceleração. Sempre se tem a impressão de que a vida se esvai sem controle e de que o tempo foge (tempus fugit) de qualquer domínio humano.

\footnotetext{
${ }^{1}$ Doutor em Direito pela Universidade Veiga de Almeida - UVA; mestre em Direito pela Universidade Federal de Pernambuco - UFPE; Licenciado em Filosofia pela Universidade Cruzeiro do Sul; Pesquisador do GGINNS - Research Group on Global Comparative Law: Governance, Innovation and Sustainability.
} 
Mas, que é o tempo - afinal? Que é vida - afinal? Os tempos são alienantes e a pessoa humana talvez tenha perdido a vontade de procurar a boa vida, fruto do equilíbrio entre trabalho e contemplação. Contra esse status quo é que urge oferecer uma nova visão do tempo como oportunidade (Kairós) e não como mera cronologia (Cronos).

Na mitologia grega, dois deuses personificam os sentidos possíveis para a noção de tempo: Cronos e Kairós. Essas ideias são interessantes para desvelar o sentido mais originário do conteúdo temporal de uma regra envolvendo o tempo como no caso do teletrabalho:

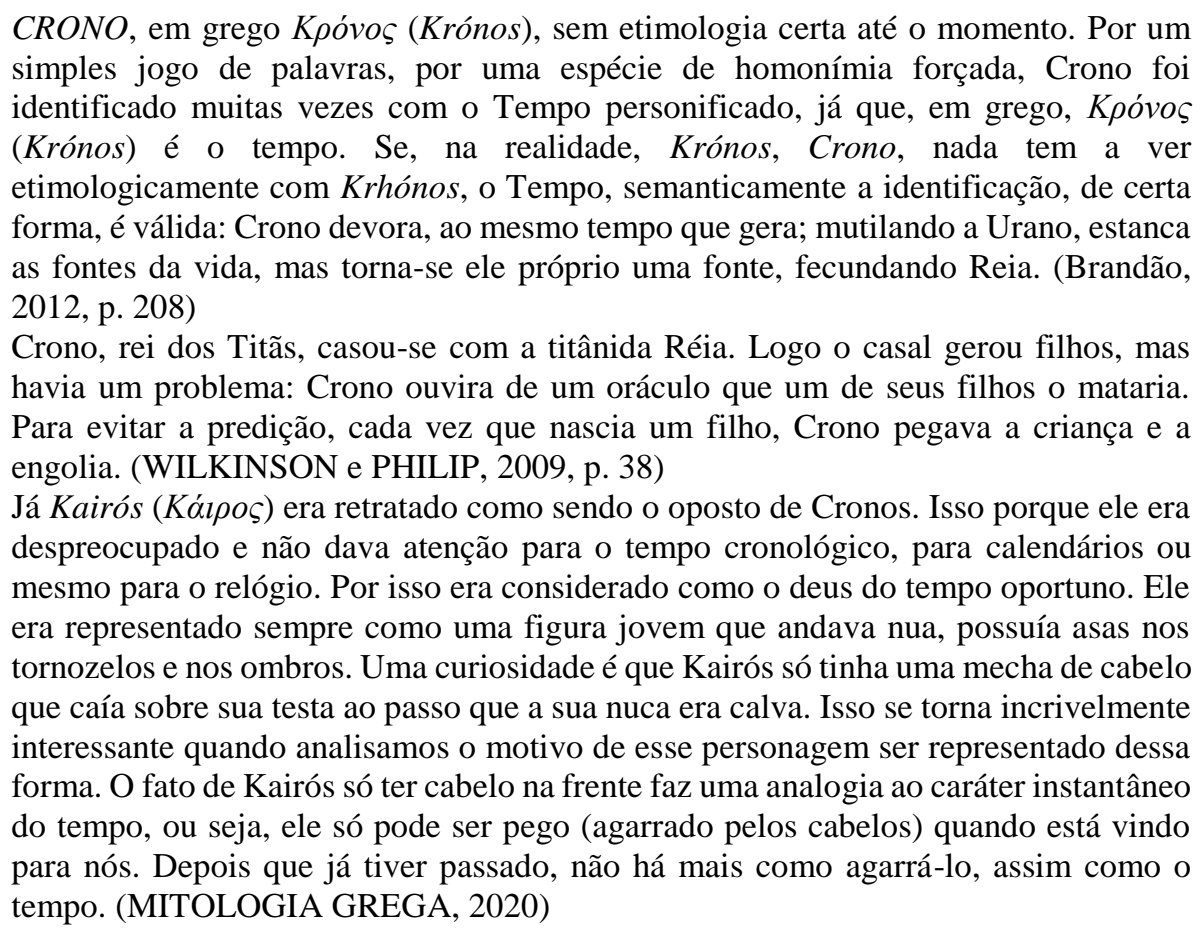

Essas duas contribuições mitológicas ajudam a esclarecer a temporalidade que marca a vida humana, pondo em evidência o tempo em suas dimensões qualitativa (Kairós) - ordem existencial, vivências, percepções e quantitativa (Cronos) - horas e calendários.

O trabalho alberga várias formas de ser exercido e uma delas é o teletrabalho. É fruto da revolução tecnológica. Veio com o discurso de concessão de mais tempo ao trabalhador como abertura à possibilidade do ócio, do lazer, da contemplação.

Entretanto o que se percebe muitas vezes é que o discurso libertário velava a possibilidade de uma nova escravidão a partir do rompimento dos limites formais do tempo ou da jornada de trabalho tradicionais, revelando que a alternativa poderia converter-se em descontrole do tempo de trabalho, fazendo com que o trabalhador passasse a trabalhar mais do que antes.

Vive-se na sociedade do desempenho, na qual o trabalhador se transformou numa espécie de empresário de si mesmo. Ele se vigia, se cobra e se impõe mais e mais performance e produtividade, tudo isso regado à sensação de que ele é livre. Nada e ninguém o vigia, o 
espreita. Mas ele é simultaneamente o vigia e o vigiado. O panóptico não é algo externo a si, o modelo de vigilância está internalizado. O trabalhador é o novo panóptico de si mesmo.

Nesse contexto, urge exigir o direito à desconexão. Por quê? Porque vive-se a todo instante conectado em redes. Assim, sem uma ruptura temporal com a conexão, falar em descanso, lazer, convivência familiar, cultivo de amizades ou dignidade humana, tudo se transforma em mera retórica.

A visão simplista e, portanto, redutora do tempo a mera questão monetária empobrece essa discussão. O tempo, ao ser a própria essência da vida - vida é tempo e tempo é vida, ganha dimensão que não pode ser circunscrita a mero cálculo econômico.

O teletrabalho já é uma realidade e se tornará o principal modelo de trabalho em curto prazo. Urge que os trabalhadores e empregadores se preparem para essa nova onda e tomem todas as cautelas para não se tornarem escravos desse novo regime laboral.

\section{TELETRABALHO}

Convém deixar claro, de início e para que não pairem dúvidas, que o teletrabalho já era uma realidade antes da pandemia do Covid-19. A quadra atual apenas intensificou o uso desse regime laboral em face das exigências sanitárias que acabaram por impor a necessidade de distanciamento social. Não é correto pois afirmar que o teletrabalho surge com a pandemia.

\subsection{Conceituação}

Para Pino Estrada (2017, p. 11):

[...] o teletrabalho é aquele realizado com ou sem subordinação por meio do uso de antigas e novas formas de telecomunicação em virtude de uma relação de trabalho, permitindo a sua execução à distância, prescindindo da presença física do trabalhador em lugar específico de trabalho.

Ressalta do conceito acima alguns elementos definidores do que se deva conceber conceitualmente como teletrabalho: a) relação de trabalho; b) presença ou não de subordinação e c) ausência da presença física do trabalhador no ambiente laboral tradicional.

Em outras palavras, o teletrabalho é uma modalidade de relação de trabalho submetida ou não à subordinação do empregado ao empregador cuja presença física do trabalhador é dispensada.

A Organização Internacional do Trabalho - OIT (2021) adota o seguinte conceito de teletrabalho: 
Considera-se teletrabalho a prestação laboral realizada com subordinação jurídica, habitualmente fora da empresa e através do recurso a tecnologias de informação e de comunicação.

O conceito adotado pela OIT confunde teletrabalho com home office. Marca o home office a presença da subordinação, ou seja, o empregador tem todos os meios de controle disponíveis para exercer seu poder de mando, fato esse inexistente no teletrabalho. No teletrabalho há muito mais autonomia para o trabalhador exercer seus serviços. O teletrabalho foca em resultados e aumento de produtividade, intensificando a responsabilidade do trabalhador pelo êxito de suas atividades laborais. Pode-se afirmar que o home office é uma espécie de "prototeletrabalho", a sua ancestralidade.

Quanto à ausência da presença física do trabalhador, isso tem de ser entendido de forma ampla, especialmente em face dos avanços tecnológicos que já permitem que empregadores monitorem seus empregados praticamente 24 horas por dia. Não se deve reduzir a análise à noção de home office, pois, assim, estar-se-ia desconsiderando todo o aparato tecnológico disponível e em franca expansão e aprimoramento. Isso fica demonstrado na conceituação da OIT sobre teletrabalho.

A realidade hoje é a de que todos estão conectados aos smartphones, e-mails e redes sociais praticamente em tempo integral e em qualquer lugar.

A noção de tempo e de espaço está flexibilizada, fazendo com que haja uma intensa interação entre a vida de carne e osso e a "vida virtual", ao ponto delas se confundirem ou se mesclarem de tal forma que, classificações clássicas como jornada de trabalho, tempo de descanso e outras, necessitem de novas visões para darem conta dessa complexidade hodierna.

O trabalho se libertou da noção costumeira de espaço geográfico. O binômio empresatrabalhador não é mais suficiente para dar conta da complexidade do mundo laboral atual. Há uma desmaterialização ou virtualização da própria geografia laboral.

Se adotado o regime laboral do teletrabalho, pouco importa se o trabalhador desempenha suas atividades na empresa, em casa, na rua, numa cafeteria ou em qualquer outro lugar. Isso se tornou completamente irrelevante diante do avanço tecnológico. Cada vez mais, a velocidade e a segurança do tráfego de informações são incrementadas, permitindo que a comunicação evolua em sua instantaneidade. A Consolidação das Leis do Trabalho - CLT reforça esse entendimento em seu art. 75-B.

Configura-se, hoje, uma concepção superada exigir, por exemplo, que o trabalhador em regime de teletrabalho desenvolva suas atividades em casa. Isso em nada se coaduna com a sociedade em rede na qual se está imerso. É ainda resquício de uma sociedade da vigilância, na qual importava ter controle absoluto sobre os corpos das pessoas como bem percebeu Michel Foucault (1987). Posturas como essas são anacrônicas, em outras palavras, para usar a 
etimologia do vocábulo fora (ana) do tempo (cronos), ou contrárias ao que é moderno, dito de outra forma, extemporâneas, obsoletas, retrógradas, ultrapassadas.

Cada um carrega consigo o campo de trabalho ${ }^{2}$ onde quer que esteja. É preciso compreender o trabalho, como categoria analítica, em sua historicidade, sob pena de perder o bonde da história. O tempo de grandes escritórios, de palácios e grandes estruturas físicas para o exercício de qualquer trabalho, seja no setor privado, seja no setor público, está em franco declínio, faz parte ainda de um passado que teima em ser estático, petrificado. Mas tudo flui, não se repete, apesar da inútil resistência de "recônditos (amuados) da sociedade" (ULRICH BECK, 2011, p. 209).

\subsection{As noções de tempo e de espaço}

Sempre foi a partir da noção clássica de "relação de emprego" que os termos tempo e espaço foram concebidos no âmbito do Direito do Trabalho. A tônica imposta hoje pelos avanços tecnológicos é a de flexibilização dos conteúdos conceituais tradicionais.

Até mesmo a noção de emprego a cada dia sofre os ataques dos avanços tecnológicos, ao ponto de se dizer que os tempos são de menos empregos e de mais trabalhos.

Pode-se chegar à afirmação de que os centros norteadores do Direito do Trabalho estão em franco processo de descentralização ou virtualização em face das transformações das relações de trabalho e da evolução das tecnologias da informação.

Fala-se hoje em "flexitempo" (SENETT, 2009, p. 65-69):

[...] um trabalhador em flexitempo controla o local do trabalho, mas não adquire maior controle sobre o processo do trabalho em si. A essa altura, vários estudos sugerem que a supervisão do trabalho muitas vezes é na verdade maior para os ausentes do escritório do que para os presentes. Os trabalhadores, assim, trocam uma forma de submissão ao poder - cara a cara - por outra, eletrônica; a microadministração do tempo avança para a tela do computador. O trabalho é fisicamente descentralizado, o poder sobre o trabalhador é mais direto [...] o tempo da flexibilidade é o tempo de um novo poder. Flexibilidade gera desordem, mas não livra das limitações. (negrito acrescentado)

O que está em jogo? A gestão do tempo de trabalho ou, em palavras simples, o tempo de vida do trabalhador que empresta a sua força produtiva para os tomadores desse tempo de vida.

Isso tudo se torna cada vez mais complexo, tendo em vista que o trabalho possa ser realizado em qualquer lugar e a qualquer instante. E o que há de mais importante para o trabalhor do que o tempo que ele aloca para o trabalho? Nesse contexto, como pensar

\footnotetext{
${ }^{2}$ Para melhor compreensão dessa noção de "campo de trabalho", cunhada por Pierre Bourdieu, ver Catani (2017, p. 352-354).
} 
atualmente a duração do trabalho, se o "chão da fábrica" se desmaterializou e as paredes dos escritórios não existem mais? Tempo e espaço: dois centros que se descentralizaram. Isso pode gerar riscos para o trabalhador.

Esse cenário não passou despercebido de Beck (2011, p. 207-209):

\begin{abstract}
O fato de que a norma do trabalho vitalício de jornada integral foi suplantada por formas plurais de flexibilização da jornada de trabalho é uma constatação que já invadiu mesmo os últimos recônditos (amuados) da sociedade.

[...] O vínculo cooperativo empresarial, ao menos em certos setores (administração, escritório, gerência, prestação de serviços), já pode ser gerado por meios eletrônicos e portanto organizado de forma descentralizada, "espacialmente difusa" e "espacialmente independente".

[...] os ganhos de soberania obtidos pelos trabalhadores sobre seu trabalho com a flexibilização espacial do trabalho assalariado podem ser combinados com uma privatização dos riscos que o trabalho oferece à saúde física e psicológica. Normas de segurança no trabalho escapam ao controle público nas formas de trabalho descentralizado e os custos por desconsiderá-las ou suspendê-las são transferidos aos próprios trabalhadores (assim como as empresas acabam economizando os custos da organização central do trabalho assalariado, desde a manutenção das instalações até a proteção dos equipamentos eletrônicos).
\end{abstract}

A flexibilização de tempo e de espaço não pode servir de isenção da responsabilidade em relação à saúde e segurança do trabalhador no regime de teletrabalho. Essa é uma forte preocupação de Ulrich Beck e não se pode negligenciá-la.

Isso implica limitar temporalmente o regime do teletrabalho, como, por exemplo, fixando um lapso no qual ele poderia ser prestado, v.g., de 6 ou 8 da manhã às 18 ou 20 da noite (extensão média de 12 horas em disponibilidade). Nessa régua, nem abaixo e nem acima, sob pena de configuração de prestação de serviço extraordinário (horas extras) ou banco de horas, o (tele)trabalhador estaria em disponibilidade e/ou efetivamente trabalhando. Estar em teletrabalho não pode significar encontrar-se disponível 24 horas por dia, 7 dias por semana, 30 dias por mês, 365 dias por ano. Há de existir limites, sob pena de se inviabilizar a vida privada e o tempo de lazer do trabalhador. $\mathrm{O}$ trabalho necessita harmonizar-se com a vida familiar ${ }^{3}$.

Para Columbo e Massoni (2017, p. 26):

As fronteiras entre o tempo de trabalho e o tempo livre, atualmente, em especial no teletrabalho, estão cada vez mais incertas e fluidas, o que exige novos esforços interpretativos e propostas para uma legislação adequada, até o momento inexistente.

Remarque-se, estar em teletrabalho não pode representar viver apenas em, do e para o trabalho. Há vida além dos limites laborais. O tempo é no fundo a substância que define a própria noção de vida.

\footnotetext{
${ }^{3}$ Conforme o art. XXIV da Declaração Universal de Direitos do Homem, de 1948: "XXIV - todo homem tem direito a repouso e lazer, inclusive à limitação razoável das horas de trabalho e a férias remuneradas periódicas".
} 
Jorge Luís Borges (1974, p. 771) diz que "El tiempo es la sustancia de que estoy hecho. El tiempo es un río que me arrebata, pero yo soy el río; es un tigre que me destroza, pero yo soy el tigre; es un fuego que me consume, pero yo soy el fuego"4.

Convém deixar salientado que o que se busca com a modalidade "teletrabalho", em apertada síntese, é, de um lado, a otimização do tempo de trabalho e a melhoria da qualidade de vida do trabalhador, e, do outro, o recebimento de um serviço de qualidade e com mais produtividade com baixo custo na manutenção do estabelecimento empresarial.

Outro aspecto muito importante, e que ainda não recebeu a devida atenção da classe política e dos pesquisadores nacionais, diz respeito à possibilidade de o teletrabalho ser mais uma importante ferramenta para o fomento da interiorização da economia, propiciando condições para que se possa pensar em políticas públicas incentivadoras, por exemplo, de um "êxodo urbano", desafogando, dessa maneira, os índices de ocupação dos espaços nos maiores centros urbanos, o que tem contribuído para uma exacerbação da demanda por serviços públicos, além de piora em questões de saúde, de meio ambiente, de mobilidade, de educação e de segurança pública, para citar algumas.

Para superar as atuais barreiras de uma possível interiorização, muitas das atuais dificuldades necessitariam ser superadas e uma delas diz respeito à precariedade tecnológica de expressiva parte das cidades interioranas, mormente a questão do acesso à internet com qualidade e preços razoáveis.

\title{
1.3 Aspectos jurídicos e econômicos
}

\subsubsection{Aspectos jurídicos}

$\mathrm{O}$ art. $6^{\circ}$ da CLT equipara o trabalho realizado no estabelecimento do empregador ao executado no domicílio do empregado e ao realizado à distância:

\begin{abstract}
Art. $6^{\circ}$ Não se distingue entre o trabalho realizado no estabelecimento do empregador, o executado no domicílio do empregado e o realizado a distância, desde que estejam caracterizados os pressupostos ${ }^{5}$ da relação de emprego.

Parágrafo único. Os meios telemáticos e informatizados de comando, controle e supervisão se equiparam, para fins de subordinação jurídica, aos meios pessoais e diretos de comando, controle e supervisão do trabalho alheio.
\end{abstract}

A CLT ainda resiste (inutilmente) aos ventos revolucionários da tecnologia e não consegue de todo retirar suas raízes do solo da década de 40. Ainda se aferra à vetusta subordinação, além de usar expressão de origem militar como "comando", como se o

\footnotetext{
4 Tradução livre: "O tempo é a substância de que sou feito. O tempo é um rio que me arrasta, mas eu sou o rio; é um tigre que me destroça, mas eu sou o tigre; é um fogo que me consome, mas eu sou o fogo".

${ }^{5}$ São pressupostos da relação de emprego, nos termos do art. $3^{\circ}$ da CLT: o trabalho prestado pessoalmente por pessoa física, de forma não eventual, mediante subordinação, com a presença de onerosidade, subordinação.
} 
trabalhador sofresse de alguma minoridade ou devesse ser tratado como um soldado. Está preocupada em controlar corpos e não em fomentar a produtividade, deixando o trabalhador autônomo e responsável por suas atividades laborais.

Pelo inciso III do art. 62 da CLT, aos empregados em teletrabalho não se aplica o Capítulo II relativo à duração do trabalho (jornada de trabalho e períodos de descanso). Esse dispositivo consolidado é de duvidosa constitucionalidade, pois o teletrabalho não altera o vínculo empregatício, configurando-se apenas como uma modalidade de prestação de serviços contratados, restando, dessa forma, sob a incidência da CLT reguladora da jornada de trabalho e de períodos de descanso.

Nesse ponto, a CLT está atenta aos tempos atuais e complexos da sociedade da informação ou em rede que diluem as noções clássicas sobre tempo e espaço de trabalho.

Os arts. 75-A a 75-E da CLT, incluídos pela Lei $\mathrm{n}^{\circ}$ 13.467, de 2017 (reforma trabalhista), trazem regras específicas para o regime de teletrabalho. O art. 75-B assim conceitua o teletrabalho:

Art. 75-B. Considera-se teletrabalho a prestação de serviços preponderantemente fora das dependências do empregador, com a utilização de tecnologias de informação e de comunicação que, por sua natureza, não se constituam como trabalho externo.

Parágrafo único. $\mathrm{O}$ comparecimento às dependências do empregador para a realização de atividades específicas que exijam a presença do empregado no estabelecimento não descaracteriza o regime de teletrabalho. (negritos acrescentados)

Tratam da forma de pactuação do contrato de teletrabalho (art. 75-C), das disposições relativas à responsabilidade pelos equipamentos e infraestrutura para a prestação do teletrabalho (art. 75-D) e das medidas para a prevenção de doenças e acidentes de trabalho (art. 75-E).

O inciso VIII do art. 611-A da CLT dispõe que a convenção coletiva e o acordo coletivo de trabalho têm prevalência sobre a lei quando, entre outros, dispuserem sobre teletrabalho. De duvidosa constitucionalidade no que respeita à possibilidade de não submissão do regime de teletrabalho às regras celetistas de duração da jornada de trabalho e de períodos de descanso.

Aqui a CLT prossegue adotando a tendência legislativa de se dar preponderância do negociado sobre o legislado, dessa feita no que tange ao teletrabalho.

Aspecto relevante reside em saber se no âmbito do teletrabalho é possível ou não a configuração de jornada de trabalho extraordinária. Pelo disposto no art. 62 inciso I da CLT, ao teletrabalho, em princípio, não se aplicaria o pagamento de horas extras. Todavia, isso é de constitucionalidade duvidosa.

Cada caso/função devem ser analisados, devendo-se observar "a carga diária de tarefas; o tempo para a realização de cada tarefa; o prazo estipulado para a entrega da tarefa; o número 
de toques, programas de controle de acesso e de jornada de trabalho etc." (Columbo e Massoni, 2017, p. 37).

\subsubsection{Aspectos econômicos}

Do ponto de vista do empregador, podem ser listadas algumas vantagens do teletrabalho (Columbo e Massoni, 2017, p. 34): a) economia de espaço nos locais de trabalho; b) economia de energia; c) economia quanto a intervalos de jornada; d) aumento na produtividade; e) surgimento de novos produtos; f) internacionalização e descentralização da produção. Desvantagens (MASSI, p. 89): “[...] As desvantagens, por sua vez, estão atreladas à maior dificuldade de fiscalização dos trabalhos, aumentando-se o risco de quebras de sigilo, com transmissão de informações internas e confidenciais da empresa a concorrentes".

Na ótica do empregado (Columbo e Massoni, 2017, p. 35): a) maior disponibilidade para a convivência familiar; b) racionalização das atividades profissionais; c) redução de gastos com transporte e alimentação; d) redução da perda de tempo com deslocamentos no trânsito e e) facilitação de trabalho para pessoas com deficiência e para idosos. Desvantagens (MASSI, p. 89): "1) isolamento do trabalhador em relação aos demais colegas de trabalho; 2) dificuldade de inserção e de promoção na carreira; 3) menor nível de proteção social, em razão da menor tutela sindical e administrativa; 4) aumento de conflitos familiares, pela dificuldade em se distinguir a fronteira entre o trabalho e o convívio com a família; 5) afronta à intimidade do trabalhador e à de sua família; 6) aumento do risco de problemas relacionados à saúde e à segurança do trabalho, em razão da menor esfera de vigilância do empregador sobre o empregado".

Para a sociedade: a) redução da poluição; b) redução de acidentes de trânsito e c) racionalização da mobilidade urbana. Desvantagens (MASSI, p. 90): “[...] podem advir de problemas de saúde decorrentes do teletrabalho, trazendo custos para a Previdência Social".

Entretanto é importante pontuar que há efetivamente gastos também da Previdência Social com o alto índice de acidentes com o trabalhador durante o deslocamento para seus locais de trabalho. Não há estudo estatístico, ainda, que possa demonstrar o aumento de despesas com a saúde do trabalhador no teletrabalho em relação ao modelo tradicional de prestação de serviço local.

Sob o viés econômico, é inequívoca a relação de dependência entre teletrabalho, produtividade e redução de gastos. A tecnologia tem papel preponderante como fomentador dos níveis produtivos. Como no teletrabalho o tempo é otimizado, logo, por inferência lógica, a produtividade salta em comparação ao modelo de trabalho presencial e suas características (deslocamento, alimentação, estresse e seus custos).

Além disso, a economia para a empresa (pública ou privada) com a redução de despesas de manutenção de todo o aparato físico/local/espacial do trabalho é noticiada diariamente nos 
jornais de grande circulação, além dos dados efetivos estampados nos orçamentos públicos ${ }^{6}$ e privados.

\title{
1.4 Trabalho imaterial
}

O teletrabalho está em íntima relação com a noção de trabalho imaterial. Aqui se trabalhará com as noções teóricas de Castells, Lazzarato e Gorz.

Lazzarato assim entende por trabalho imaterial:

\begin{abstract}
Em resumo, podemos distinguir três tipos de trabalho imaterial que impulsionam o setor de serviços, no topo da economia informacional. O primeiro está envolvido numa produção industrial que foi informacionalizada e incorporou tecnologia de comunicação de um modo que transforma o próprio processo de produção. A atividade fabril é vista como serviço e o trabalho material da produção de bens duráveis mistura-se com o trabalho imaterial e se inclina na direção dele. O segundo é o trabalho imaterial de tarefas analíticas e simbólicas, que se divide na manipulação inteligente e criativa de um lado e nos trabalhos simbólicos de rotina de outro. Finalmente, a terceira espécie de trabalho imaterial envolve a produção e a manipulação de afetos e requer contato humano (virtual ou real), bem como trabalho do tipo físico. Esses são os três tipos de trabalho que impulsionam a pós-modernização da economia global. (LAZZARATO e NEGRI, 2003, p. 314).
\end{abstract}

O trabalho imaterial surge no contexto do que Castells (2000, p. 50) denomina de "informacionalismo", fenômeno decorrente do avanço crescente das tecnologias da informação. Para esse pensador, a revolução tecnológica representa:

[...] um evento histórico da mesma importância da Revolução Industrial do século XVIII, induzindo um padrão de descontinuidade nas bases materiais da economia, sociedade e cultura.

E muitos ainda não se deram conta de que hoje se vive num mundo completamente modificado pela revolução tecnológica, que os tempos são de sociedade em rede, que tanto a economia quanto a sociedade e a cultura foram paradigmaticamente afetadas, logo o trabalho não poderia passar incólume às lufadas desses novos ares.

A informação, que antes dessas alterações era vista como parte integrante da produção, convola-se em produto. Basicamente, o teletrabalho trabalha (produz) com informações. Inequivocamente que tal produção exige do trabalhador criatividade, certo senso estético.

\footnotetext{
${ }^{6}$ Governo reduz gastos públicos em R \$ 466.4 milhões com teletrabalho. Ago 2020 (disponível em: <https://www.gov.br/pt-br/noticias/financas-impostos-e-gestao-publica/2020/08/governo-reduz-gastos-publicosem-r-466-4-milhoes-com-teletrabalho>). Governo federal economiza R \$ 691,9 milhões em despesas administrativas com trabalho remoto de servidores. Set 2020 (disponível em: <https://www.gov.br/economia/ptbr/assuntos/noticias/2020/setembro/governo-federal-economiza-r-691-9-milhoes-em-despesas-administrativascom-trabalho-remoto-de-servidores-1>).
} 
Isso tem impactado grandes setores que empregavam em larga escala, como o setor industrial, que cada vez mais se equipa com os artefatos tecnológicos diminuindo com isso o número de empregos ofertados. Nesse panorama, trabalhos de cunho mais intelectualizado têm sido ofertados em número crescente pondo em evidência a preponderância do setor de serviços.

O trabalho imaterial não produz uma mercadoria palpável, material (por isso o “i” em imaterial). Dele resulta um serviço ou uma informação. Para Gorz (2005, p. 29), as balizas do trabalho imaterial devem ser encontradas na necessidade de "julgamento, intuição, senso estético, nível de formação e informação, a faculdade de aprender e de se adaptar a situações imprevistas".

Em países periféricos e de modernidade tardia como o Brasil, ainda é uma minoria que produz trabalhos imateriais, já que a maioria dos trabalhadores têm baixa qualificação e muitos sequer têm acesso aos avanços tecnológicos.

\subsection{Saúde e segurança}

Logo de saída, é preciso deixar registrado que o trabalhador sob vínculo empregatício em regime de teletrabalho já conta com a proteção de todas as normas vigentes pertinentes à saúde e segurança no trabalho. Em outras palavras, o teletrabalho não altera a natureza jurídica de empregado, mas somente a organização da prestação do trabalho.

A segurança e a saúde no trabalho são direitos fundamentais positivados no texto constitucional: art. $5^{\circ}$, caput, art. $6^{\circ}$, art. $7^{\circ}$, XXII e XXVIII. Também incidem protetivamente sobre o teletrabalho: O Capítulo V (Da Segurança e da Medicina do Trabalho) da CLT e as Normas Regulamentares contidas na Portaria ${ }^{\circ} 3.217$, de 1978, do Ministério do Trabalho e Emprego (hoje atribuições do Ministério da Economia).

\section{O TRABALHO EM TEMPOS DE COVID-19}

O mundo foi assolado por um inimigo invisível e comum a todos - o coronavírus. O novo coronavírus, descoberto em dezembro de 2019, na China, é denominado Covid-19, causa infecção respiratória aguda, tornou-se uma pandemia por atingir diversos países do mundo e ser de fácil propagação, exigindo medidas de higiene e isolamento como melhor forma de contenção. Os dados alarmantes da $\mathrm{OMS}^{7}$ mostram casos identificados do Covid-19 e milhões de vidas ceifadas.

O que antes era mais uma modalidade de organização da prestação do trabalho, o teletrabalho se transformou na melhor alternativa para a preservação de postos de trabalho.

\footnotetext{
${ }^{7}$ Latest update - Coronavirus disease (COVID-19). Acesso em: 07 mar 2021. (WHO, 2021).
} 
Os tempos são de distanciamento social para evitar a propagação do coronavírus. A realização de trabalho na modalidade ou regime de teletrabalho atende ao momento histórico pelo qual passa a humanidade.

Apesar de já existir antes mesmo da pandemia, o teletrabalho sofreu um impulso não esperado e com resultados positivos, ao ponto de empresas declararem que o manterão independente do quadro pandêmico.

Mais de $65 \%$ das empresas que se viram forçadas a adotar o teletrabalho afirmam que manterão o novo regime incorporado às suas rotinas laborais, porque conseguiram "enxugar vários custos" $"$.

É preciso deixar claro que a pandemia não criou o teletrabalho, apenas o dinamizou como alternativa em face das restrições sanitárias. A pandemia foi e está sendo um grande teste para esse regime de trabalho e já se pode afirmar que ele está passando com louvor pelos desafios que lhe foram impostos.

O incremento do uso do teletrabalho deixou algumas lições: percepção do aumento na produtividade; redução de demandas por escritórios; maior flexibilidade organizacional; melhores tempos de respostas; motivação; meio ambiente mais limpo; redução de consumo de energia e menos dependência de combustíveis fósseis.

\section{SOCIEDADE DO CANSAÇO E DO DESEMPENHO}

O filósofo Byung-Chul $\mathrm{Han}^{9}$ tem se especializado em radiografar o funcionamento da sociedade atual, sua estrutura, suas mazelas, suas doenças, sua temporalidade, bem como sua relação com o trabalho (vita activa $)^{10}$ e a contemplação (vita contemplativa) ${ }^{11}$.

O teletrabalho, ao fim e ao cabo, não passa de um sintoma do que Han intitula de "Sociedade do cansaço".

Como salienta PAIXÃO JÚNIOR (2020, p. 83-84) em face do conjunto da obra haniana:

\footnotetext{
${ }^{8}$ Disponível em: 〈https://www.deskcoworking.com.br/home-office-e-trabalho-remoto/>. Acesso em 7 mar 2021.

9 Byung-Chul Han nasceu na Coreia do Sul (Seul), mas fixou-se na Alemanha, onde estudou Filosofia na Universidade de Friburgo e Literatura Alemã e Teologia na Universidade de Munique. Em 1994, doutorou-se em Friburgo com uma tese sobre Martin Heidegger. É professor de Filosofia e Estudos Culturais na Universidade de Berlim e autor de inúmeros livros sobre a sociedade atual, dentre os quais (traduzidos para o português): "Sociedade do cansaço"; "Sociedade da transparência"; "Agonia de eros"; "Topologia da violência"; "Hiperculturalidade, cultura e globalização"; "Filosofia do zen-budismo"; "No enxame - perspectivas do digital"; "Psicopolítica - o neoliberalismo e as novas técnicas de poder"; "Bom entretenimento"; "O que é o poder?"; "A salvação do belo"; "Morte e alteridade" e o "Aroma do tempo - um ensaio filosófico sobre a arte da demora". 10 "Hannah Arendt, em especial, retomou e atualizou as distinções aristotélicas entre práxis e poiésis, distinguindo na "atividade do trabalho", no "operar" e no "agir" as dimensões fundamentais da atividade humana (Vita activa, 1960, cap. I, § $1^{\circ}$ )" (ABBAGNANO, 2007, p. 8).

11 "Ideal de vida dedicada exclusivamente ao conhecimento" (ABBAGNANO, 2007, p. 231-232).
} 


\begin{abstract}
Han, em suas obras, radiografa a sociedade atual, conforme sua visão filosófica, pondo em evidência vários aspectos, podendo ser destacados alguns para os fins desta pesquisa: a autoexploração; a comunicação; o jardim; o outro e o tempo.

Seu bisturi epistêmico disseca os males atuais, expondo suas entranhas: o inferno do igual; a síndrome de burnout; a expulsão do diferente; o desempenho como meta de vida; a exposição obscena ou pornográfica de si mesmo; a depressão; o excesso de informação; o hipercapitalismo, que transforma tudo em mercadoria, e a transparência.

Suas críticas são impiedosas ao neoliberalismo e à glorificação do trabalho como um fim em si mesmo. O trabalho está concebido de modo inflacionário: em toda parte ele é cultuado como o caminho, a verdade e a vida.

Os textos de Byung-Chul Han convidam à resistência do indivíduo na sociedade pósmoderna do trabalho, cuja ambiência mascarada de liberdade ilimitada acaba produzindo a exaustão de seu ser, a queima da alma, o esgotamento e autoagressão ou autoexploração.

A digitalização da própria vida, aliada à escassez de tempo para a reflexão, bem como o vazio dos relacionamentos, além da servidão consentida (voluntária), pela via da autoexploração, são temas problematizados pelo filósofo. Han convoca à recuperação da capacidade contemplativa como alternativa de compensação da hiperatividade destrutiva forjada no ritmo acelerado de vida que normalmente é imposto na sociedade contemporânea.
\end{abstract}

Esse novo perfil do sujeito do desempenho, aliado aos novos recursos tecnológicos, os quais permitem, por exemplo, que se trabalhe de qualquer lugar para qualquer empregador, como que derruba os muros limítrofes da concepção tradicional de local de trabalho e, com isso, também ocorre uma ressignificação do tempo de trabalho, não para diminuir jornadas, mas, ao contrário, o que se observa é um incremento de horas de trabalho.

O excesso de trabalho e desempenho agudiza-se numa autoexploração. Essa é mais eficiente que uma exploração do outro, pois caminha de mãos dadas com o sentimento de liberdade. O explorador é ao mesmo tempo o explorado. Agressor e vítima não podem mais ser distinguidos. Essa autorreferencialidade gera uma liberdade paradoxal que, em virtude das estruturas coercitivas que lhe são inerentes, se transforma em violência. Os adoecimentos psíquicos da sociedade de desempenho são precisamente as manifestações patológicas dessa liberdade paradoxal. (HAN, 2017, p. 30)

O paradoxo identificado por Han é cruel, pois faz do sujeito o explorador de si próprio em nome do desempenho, passando a falsa percepção de que ele é livre em suas escolhas. Não há liberdade, mas submissão ao desempenho. Antes de ser liberdade, trata-se de coação, ainda que imperceptível na maior parte das vezes, pois vítima e algoz estão reduzidos na mesma pessoa.

O cerne do problema é, de fato, o tempo de vida calculado como tempo de trabalho. Há no inconsciente coletivo a concepção de que a vida humana tem necessariamente que estar atrelada ao trabalho ativo.

Nesse diapasão, o teletrabalho, sintoma da sociedade do cansaço e do desempenho, se não for devidamente normatizado, pode contribuir para aprofundar a exploração do tempo existencial do trabalhador, caso não haja delimitação clara entre tempo de trabalho e tempo de 
descanso com desconexão dos dispositivos tecnológicos que prendem o trabalhador ao seu teletrabalho.

\title{
4. DIREITO À DESCONEXÃO
}

Um efeito colateral do avanço tecnológico, na visão de Goldschimidt e Graminho (2020, p. 1), é a criação da "figura do trabalhador ubíquo (onipresente), ou seja, aquele que está disponível em qualquer lugar e a qualquer momento". Os tempos hoje são de hiperconexão. Eles alertam para o fato de que:

\begin{abstract}
A nova organização do trabalho fundamentada nas novas tecnologias passou a permitir o surgimento de novas modalidades de prestação de serviços, como, por exemplo, o teletrabalho, o crowdwork, o work-on-demand via apps (trabalho sob demanda via aplicativos), criando uma nova espécie de escravatura ou ainda servidão voluntária, isso porque os indivíduos passaram a sofrer com a hiperconexão, ou seja, o trabalho pode ser prestado 24 horas por dia, 7 dias por semana, o que indubitavelmente acaba repercutindo nos direitos fundamentais básicos dos trabalhadores, como o direito ao lazer, à saúde, à vida, à liberdade, entre outros. (GOLDSCHIMIDT E GRAMINHO, 2020, p. 59-60) (negritos acrescentados)
\end{abstract}

O diagnóstico é sombrio, os trabalhadores, a partir desse quadro de hiperconexão, estariam sendo afetados negativamente, sofrendo "com a falta de privacidade e de momentos de lazer, além de estarem suscetíveis a doenças como depressão, AVC, problemas cardíacos, estresse e síndrome de Burnout (resultado do estresse crônico ocasionado pelo excesso de trabalho)" (GOLDSCHIMIDT E GRAMINHO, 2020, p. 60).

Esse alerta fica ainda mais evidente em sede de teletrabalho. Para coibir o "trabalhador ubíquo (onipresente)", esses doutrinadores defendem o direito fundamental à desconexão.

Há quem afirme, como Crary (2014, p. 11-12), que o sono será a última trincheira a ser dominada pelos avanços tecnológicos. A partir dessa quebra de barreira ou de resistência, poderia se pensar em um "trabalhador sem sono" ou em um "consumidor sem sono". Para esse pensador, a partir da colonização do sono humano o mundo seria 24/7, ou seja, 24 horas por 7 dias semanais para o trabalho e o consumo.

O direito à desconexão não se encontra previsto expressamente no texto constitucional vigente. Todavia, pode-se defender que ele se sustenta na principiologia que ampara a Constituição. Parece não ser razoável e nem lógico imaginar direitos expressamente garantidos constitucionalmente, como o direito ao lazer, o direito à privacidade, o direito à saúde, sem, antes, falar em direito à desconexão, intimamente ligado à duração do trabalho. Tudo isso implica necessariamente a expressão dignidade da pessoa humana. Perfeitamente aceitável falar-se do direito à desconexão como um direito fundamental implícito.

Qual seria o alcance desse "direito à desconexão"? Ora, em sede de teletrabalho, tudo o que seja diametralmente oposto a esse regime, em outras palavras, o direito à desconexão permite ao trabalhador não responder $e$-mails; não responder demandas via redes sociais como, 
por exemplo, WhatsApp; não atender ligações telefônicas decorrentes de atividades laborais; não estar conectado em plataformas de trabalho oferecidas pelo empregador etc.

Sem essa desconexão garantida normativamente, seria impossível ao trabalhador relaxar e desconectar-se de suas obrigações laborais, sem o que não conseguiria recompor suas forças físicas e psíquicas. A noção de vida privada para o trabalhador pressupõe o direito à desconexão das atividades laborais. A pessoa humana não vive só de trabalho. Ela precisa de tempo para convivência familiar, tempo para cultivar amizades, tempo para ter lazer, tempo para se dedicar a atividades religiosas e comunitárias.

O tempo humano de vida é marcadamente finito. Quando se nasce já se é suficientemente velho para morrer. Enquanto o tempo de vida for abordado juridicamente como um simples número sem semântica, sem sentido ontológico, certamente injustiças serão praticadas e se fará letra morta tanto da dignidade humana quanto dos valores sociais do trabalho. Nivelar tempos existenciais distintos (trabalho e lazer) é desrespeito direto à dignidade humana, por não se ater à singularidade existencial de cada ser humano (trabalhador).

Não se pode mais ver no tempo existencial de um trabalhador um algo que acontece linearmente, como uma coisa que simplesmente passa ou é dada (como uma pedra ou um carro). É a vida que está em jogo em todas as suas circunstâncias.

\section{CONSIDERAÇÕES FINAIS}

No telemundo, o trabalho já é teletrabalho. Muitos é que ainda não se deram conta disso ou teimam em fazer vista grossa ao real. A verdade, como diz Schopenhauer, passa por três estágios: no primeiro, ela é ridicularizada; no segundo, ela é violentamente combatida e, no terceiro, ela é tida como uma auto evidência. O teletrabalho não é apenas um conceito, mas um fato.

As mudanças não chegam de repente, elas sempre vêm vindo. Entretanto, há fatores que funcionam como impulsionadores de certos fenômenos. A Covid-19 está sendo um catalisador do teletrabalho em todo o mundo.

A realidade costuma fazer troça de crenças e achismos, bem como de visões que insistem em opor resistência aos avanços científicos, mormente em sua versão de maior sucesso, a tecnologia.

O fato: vive-se, hoje, numa sociedade em rede, hiperconectada e que relativiza categorias analíticas como espaço e tempo. Para usar um termo de Zygmunt Bauman (2016), tudo se transforma em fluido e, com isso, escorre mais facilmente, sendo mais difícil de ser contido, represado, controlado. A imagem não é mais de uma sociedade como uma árvore de 
raiz pivotante ou axial e sim rizomática. Os centros se descentralizam. A convivência com o caos torna-se rotina.

Diante desse contexto, a CLT tem tentado normatizar as modificações que têm desestruturado os modelos tradicionais das relações de trabalho, especialmente as de cunho empregatício.

Há ainda focos bem identificados de resistência epistêmica, como, por exemplo, a noção de subordinação. Esse vocábulo, no texto consolidado, ainda carrega forte semântica haurida das estruturas da sociedade do controle e da vigilância, onde importava ter domínio sobre a mente e o corpo das pessoas, especialmente para que elas pudessem ser "úteis" à sociedade e darem a melhor performance ou produtividade para o atingimento desse desiderato (Foucault).

Como "é mais fácil desintegrar um átomo que um preconceito" (Albert Einstein), a sociedade em rede ainda convive e certamente conviverá por mais algum tempo, com essas noções-zumbi (Bauman, 2016).

A partir desse anacronismo, por exemplo, é que existe certa resistência de permitir que o teletrabalho seja realizado em qualquer lugar, pois ainda há empregadores que não se deram conta de que o trabalho se desmaterializou, e a casa não é mais o único prolongamento do local clássico de trabalho. Qualquer lugar é adequado ao teletrabalho, desde que as condições tecnológicas o permitam.

A partir dessas constatações, as seguintes considerações podem ser estabelecidas:

a) o teletrabalho cresce em progressão geométrica e tende a ser a modalidade mais utilizada para a contratação de mão-de-obra tanto manual quanto intelectual, com destaque para essa última;

b) a subordinação cada vez mais ficará mitigada em face da mobilidade concedida ao trabalhador, tanto temporal quanto espacial;

c) esse regime possibilita a otimização de espaços, quebrando a visão clássica da necessidade de grandes espaços de trabalho;

d) a flexibilidade de tempo e espaço gera motivação profissional;

e) resultados econômicos favoráveis ao trabalhador, com economia de tempo e gastos com transporte e alimentação; e

f) resultados econômicos favoráveis ao empregador, com economia de manutenção de grandes espaços de trabalho, além do incremento na produtividade com a racionalização do trabalho e a maior autonomia e motivação do empregado. 
Cautelas devem ser adotadas:

a) limitação do lapso temporal diário no qual o teletrabalho poderá ser prestado;

b) previsão de pagamento de horas extras e garantia de banco de horas, em casos excepcionais devidamente fundamentados, para os casos de extrapolação do lapso temporal diário no qual o teletrabalho poderá ser prestado; e

c) garantia do direito à desconexão, permitindo que o trabalhador se desligue dos dispositivos tecnológicos que o prendem ao seu teletrabalho.

\section{REFERÊNCIAS}

BAUMAN, Zygmunt. Modernidade líquida. Rio de Janeiro: Zahar, 2016.

BECK, Ulrich. Sociedade de risco: rumo a uma outra modernidade. São Paulo: Editora 34, 2011.

BORGES, Jorge Luís. Nueva refutación del tiempo. Obras Completas. Buenos Aires: Emecé Editores, 1974.

BRANDÃO, Junito de Souza. Mitologia grega. Volume 1. Petrópolis, Rio de Janeiro, 2012.

BRASIL. Poder Executivo. Decreto-lei $n^{\circ} 5.452$ de $1^{\circ}$ de maio de 1943 - Consolidação das Leis do Trabalho. Disponível em: <http://www.planalto.gov.br/ccivil_03/decretolei/Del5452compilado.htm.>. Acesso em: 6 mar 2021.

CASTELLS, Manuel. A sociedade em rede - A era da informação: economia, sociedade e cultura. São Paulo: Paz e Terra, 2020.

CATANI, Afrânio Mendes et al. (Org.). Vocabulário Bourdieu. Belo Horizonte: Autêntica, 2017.

COLNAGO, Lorena de Mello Rezende, CHAVES JÚNIOR, José Eduardo de Resende e PINO ESTRADA, Manuel Martín (Orgs.). Teletrabalho. São Paulo: LTr, 2017.

COLUMBO, Francesca e MASSONI, Túlio de Oliveira. Tempo de trabalho e teletrabalho. In COLNAGO, Lorena de Mello Rezende, CHAVES JÚNIOR, José Eduardo de Resende e PINO ESTRADA, Manuel Martín (Orgs.). Teletrabalho. São Paulo: LTr, 2017. 
CRARY, Jonathan. 24/7: capitalismo tardio e os fins do sono. São Paulo: Cosac Naify, 2014.

ESASHIKA, Daniel Shim de Sousa e SCHEIDEMANTEL, Rogério. Teletrabalho: experiências nacionais e internacionais. Disponível em: <https://bd.camara.leg.br/bd/handle/bdcamara/39959>. Acesso em 6 mar 2021.

FOUCAULT, Michel. Vigiar e punir. Petrópolis: Vozes, 1987.

GOLDSCHIMIDT, Rodrigo e GRAMINHO, Vivian Maria Caxambu. Desconexão: um direito fundamental do trabalhador. Rio de Janeiro: Lumen Juris, 2020.

GORZ, André. O imaterial: conhecimento, valor e capital. São Paulo: Annablume, 2005.

GOVERNO DO BRASIL. Governo reduz gastos públicos em R\$ 466.4 milhões com teletrabalho. Disponível em: <https://www.gov.br/pt-br/noticias/financas-impostos-e-gestaopublica/2020/08/governo-reduz-gastos-publicos-em-r-466-4-milhoes-com-teletrabalho>.

Acesso em 11 mar 2021.

GOVERNO FEDERAL. Ministério da Economia. Governo federal economiza R\$ 691,9 milhões em despesas administrativas com trabalho remoto de servidores. Disponível em: <https://www.gov.br/economia/pt-br/assuntos/noticias/2020/setembro/governo-federaleconomiza-r-691-9-milhoes-em-despesas-administrativas-com-trabalho-remoto-deservidores-1>. Acesso em 11 mar 2021.

HAN, Byung-Chul. Sociedade do cansaço. Petrópolis, Rio de Janeiro: Vozes, 2017.

LAZZARATO, Maurizio e NEGRI, Antonio. Trabalho imaterial: formas de vida e produção de subjetividade. Rio de Janeiro: DP\&A, 2013.

MASSI, Alfredo. Teletrabalho - análise sob a óptica da saúde e da segurança do teletrabalhador. In COLNAGO, Lorena de Mello Rezende, CHAVES JÚNIOR, José Eduardo de Resende e PINO ESTRADA, Manuel Martín (Orgs.). Teletrabalho. São Paulo: LTr, 2017.

MITOLOGIAGREGA. Mitologia Grega Br. Curiosidades sobre Deuses, monstros e heróis. Disponível em: <https://mitologiagrega.net.br/cronos-e-kairos-personificacoes-dotempo/\#: : :text=J\%C3\%A1\%20Kair\%C3\%B3s\%20era\%20retratado\%20como,o\%20deus\%20 do\%20tempo\%20oportuno.\&text=Depois \%20que\%20j\%C3\%A1\%20tiver\%20passado,10\%2 C\%20assim\%20como\%20o\%20tempo..> Acesso em: 8 mar 2021.

ORGANIZAÇÃO DAS NAÇÕES UNIDAS. Declaração Universal dos direitos Humanos. Disponível

em: <https://www.ohchr.org/EN/UDHR/Documents/UDHR_Translations/por.pdf>. Acesso em 9 mar 2021. 
ORGANIZAÇÃO INTERNACIONAL DO TRABALHO. Teletrabalho. Disponível em: <https://www.ilo.org/wcmsp5/groups/public/---ed_protect/---protrav/--ilo_aids/documents/legaldocument/wcms_127484.pdf>. Acesso em 7 mar 2021.

OLIVEIRA, Bruno Couto de. Teletrabalho no Congresso Nacional durante a pandemia de Covid-19: De modalidade inexistente à garantidora da manutenção das atividades parlamentares. Revista Científica Multidisciplinar Núcleo do Conhecimento. Ano 05, Ed. 10, Vol. 12, pp. 50-64. Disponível em: <https://www.nucleodoconhecimento.com.br/administracao/teletrabalho-no-congresso >.

Acesso em 7 mar 20121.

PAIXÃO JÚNIOR, Nilton Rodrigues da. Regras de transição de aposentadoria de servidores públicos: uma análise crítica a partir da ontologia fundamental de Martin Heidegger e do pensamento crítico de Byung-Chul Han. Tese de doutorado aprovada em 14 de dezembro de 2020 junto ao Programa de Pós-Graduação em Direito - PPGD da Universidade Veiga de Almeida - UVA.

SENETT, Richard. A corrosão do caráter: consequências pessoais do trabalho no novo capitalismo. Rio de Janeiro: Record, 2009.

WHO - World Health Organization. WHO MERS Global Summary and Assessment of Risk. Disponível em: <https://www.who.int/csr/disease/coronavirus_infections/riskassessment-august-2018.pdf?ua=1>. Acesso em: 7 mar 2021.

WILKINSON, Philip e PHILIP, Neil. Guia ilustrado Zahar - Mitologia: mitos da criação, deuses, heróis, monstros, locais míticos. Rio de Janeiro: Jorge Zahar, 2000. 